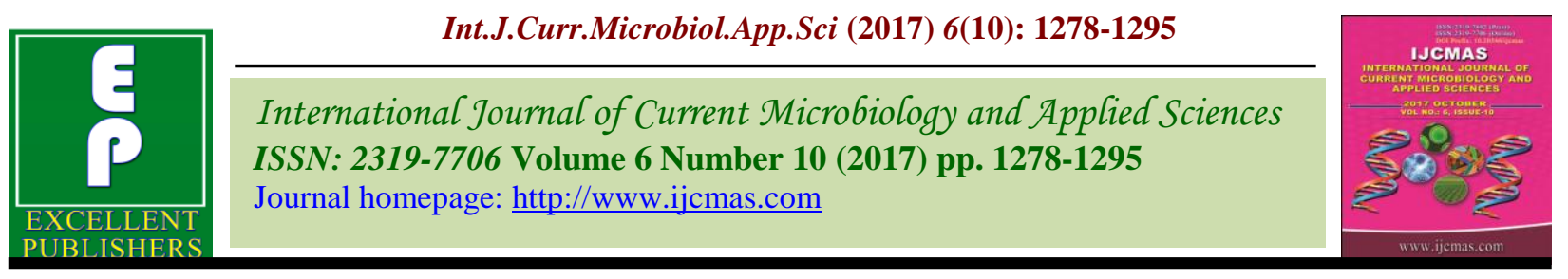

Review Article

https://doi.org/10.20546/ijcmas.2017.610.152

\title{
Influence of Milling Parameters on Head Rice Recovery: A Review
}

\author{
Jagbir Rehal $^{1 *}$, Gagan Jyot Kaur ${ }^{2}$ and A.K. Singh ${ }^{2}$ \\ ${ }^{1}$ Department of Food Science and Technology, Punjab Agricultural University, Ludhiana, India \\ ${ }^{2}$ Department of Processing and Food Engineering, Punjab Agricultural \\ University, Ludhiana, India \\ *Corresponding author
}

\begin{tabular}{|c|c|}
\hline & A B S T R A C T \\
\hline Keywords & \multirow{4}{*}{$\begin{array}{l}\text { Among the major cereals of world, rice tops both in production and } \\
\text { consumption. The production has increased manifolds but the losses during } \\
\text { the post-harvest needs to be checked. The quality of rice is judged from the } \\
\text { head rice yield (HRY). This paper reviews the various studies conducted } \\
\text { affecting the head rice yield during the last } 6 \text { decades. It gives a detailed } \\
\text { outline of various post-harvest processes, milling treatments, factors and } \\
\text { latest technologies used in improving quality and production of head rice. }\end{array}$} \\
\hline $\begin{array}{l}\text { Rice, Head rice yield, } \\
\text { Milling efficiency, } \\
\text { Degree of milling, } \\
\text { Tempering, Quality. }\end{array}$ & \\
\hline Article Info & \\
\hline $\begin{array}{l}\text { Accepted: } \\
\text { 14 September } 2017 \\
\text { Available Online: } \\
10 \text { October } 2017\end{array}$ & \\
\hline
\end{tabular}

\section{Introduction}

Rice is amongst the oldest domesticated grain in the world and its cultivation has been recorded in ancient civilisations. The total rice production sums to 472.25 million tons, China leads in the production of rice (144 million metric tons) followed by India with a total production of 106 million metric tons (FAO, 2014). It is estimated that by 2025,10 billion people will depend on rice as a main food and demand will reach about 880 Million tons.

Rice is consumed as whole grain, rice flour, rice flakes, puffed rice etc. but amongst them whole rice holds the major share in consumption pattern (IRC, 2002) Among cereals, rice is mainly consumed in the whole form after appropriate processing.
It is estimated that the post-harvest losses range from 15 to 16 percent of the rice crop out of which about 9 per cent of paddy is lost primarily due to use of old and outdated methods of drying and milling, improper and unscientific methods of storage, transport and handling (FAO, 2004).

Out of the total estimated losses in the rice crop (15-16\%) are primary due to practice of unscientific old and traditional methods of drying, milling, handling, transportation etc. Whereas two to three per cent losses are reported at the producer level (FAO, 2004).

It has been estimated that total post-harvest losses of paddy at producers' level are about 2.71 per cent of total production. 
Milling is defined as removal of husk from the paddy and converting it to edible form. The milled rice without polishing are called brown rice. Once the outer layer (bran) is removed by polishing it is converted to polished rice. The efficiency of polishing is dependent on moisture content, during the harvesting, milling, the milling conditions, type of mill employed etc.

Finally during the milling of paddy, rice is obtained along with number of rice fractions and by products viz. rough rice, milled rice, germ, rice brokens, a mixture of bran and husk. Rice quality is a combination of physical and chemical characteristics, which can be divided into four broad interrelated categories:

Processing or milling quality;

Cooking and eating quality;

Appearance quality;

Nutritive quality.

Each category is described by a specific set of criteria that collectively determine the suitability of rice for a specific market or consumer. The head rice yield / whole grain is the most important factor or rice milling and processing industry (Marchezan, 1991). As the cooking quality of broken rice is very poor, the market price with broken grains is much less than that for whole grains ( $\mathrm{Li}$ et al., 1999). The ultimate goal of the rice industry is to achieve maximum head rice yield (HRY) from the milling process.

The definitions of few terminologies which will be used in the review are given for quick reference (RKMP, 2014):

Rough rice or paddy: Defined as rice in the husk after harvesting.

Husked rice/brown rice: Rice from which only the husk has been removed retaining the bran layers and most of the germ together. Such rice is sometimes reflected to as bran rice even though there are variations having red or white bran coats.

Milled rice: Rice from which husk, germ and bran layers have been removed mechanically.

White Rice/polished rice: When the outer layers of bran are completely removed.

Parboiled rice: Rice, processed by steaming or soaking in hot water, (heating usually by steam) and drying. Parboiled paddy can be milled to various degrees or home produced in the same way as ordinary paddy. It is called as parboiled milled or parboiled hand pounded.

Broken rice: Husked, milled or hand pounded milled rice with grain size between $3 / 4^{\text {th }}$ to $1 / 4^{\text {th }}$ size of whole grain.

Head rice yield: Head rice yield is the weight percentage of rough rice that remains as whole rice (three-fourths kernel or greater) after complete milling.

Milling yield/Total yield: Milling yield is the weight percentage of rough rice that remains as milled rice; i.e., the sum of head rice and "brokens"

\section{Effect of parboiling}

Parboiling consists of soaking, steaming or hot water boiling followed by drying of the paddy. It increases milling yields, nutritional value and resistance to spoilage by insects and mould. Comparing the nutritional properties of milled and parboiled rice the latter resulted in better retention of nutrients and water soluble minerals due to its solubility and migration of nutrients to the centre. The quality of parboiled rice is assessed by its browning index and head rice (Juliano, 1985; 
Pederson et al., 1989; Heinemann et al., 2005).

The quality of parboiled rice is measured as head rice yield and browning index (BI). The effect of air temperature on BI showed that the temperature of $70^{\circ} \mathrm{C}$ or below yielded parboiled rice of tolerable light yellow color (Elbert et al., 2001). During parboiling the head rice yield varies from 68-74 per cent and yield decreases with the increase in temperature and increases with the increase in tempering time. Tempering period is the stage in which paddy is kept in a closed bin without airflow. After a sufficiently long period of tempering, the moisture profile throughout the paddy becomes uniform. It helps to maintain a uniform moisture profile in the grain, reducing the tensile strength during the first stage of drying. It also reduces the drying time, increases energy efficiency and the head rice yield. The energy efficiency is mainly dependent upon the steaming time and temperature (Li et al., 1999; Steffe, 1979; Zhang and Litchfield, 1991; Soponronnarit et al., 1999). In addition, tempering also reduces the drying time in the final stage, resulting in more effective energy utilisation.

Parboiling temperature and duration had significant influence on the hardness. Parboiling of dehusked paddy by soaking at $70^{\circ} \mathrm{C}$ for $1.5 \mathrm{~h}$ and steaming for $12 \mathrm{~min}$ (Abrol, 1983), soaking at $75^{\circ} \mathrm{C}$ followed by natural cooling (Pillaiyar and Mohandass, 1981) soaking at $70-100^{\circ} \mathrm{C}$ and cooling at room temperature for $2 \mathrm{~h}$ followed by open steaming for $20 \mathrm{~min}$ (Kar et al., 1999) have been documented. The last method reduced cooking time by $30 \%$ and saved $40 \%$ energy. They further reported an increase in hardness of 'parboiled dehusked rice' samples with the increase in steaming time. A cooking time of $11.6 \mathrm{~min}$ was employed which resulted in less sticky rice than raw rice and less hard than traditional parboiled rice (Bello et al., 2004). Steaming of parboiled rice increases the hardness thus increasing the yield of head rice (Islam et al., 2004). Study on reducing the cost of parboiling equipment by precluding the need for large boilers and steaming tanks with elaborate steam distribution systems, in addition to improvements in the quality of the parboiled rice was done by Adhikaritanayaka and Noomhorm (1998).

Recommended soaking temperature for rough rice should be $5^{\circ} \mathrm{C}$ less than the gelatinization temperature of that particular variety which is $73-86^{\circ} \mathrm{C}$ for long grain rice (Kimura et al., 1993; Fan et al., 1999). It is followed by steaming for which soaked rice should have about 30-35\% moisture content (w.b.) (Bhattacharya, 1985). The activation energies for chroma and total colour difference were 22.1 and $11.1 \mathrm{~kJ} \mathrm{~mol}^{-1}$, respectively. The colour development due to parboiling was least at low steaming pressure and short times (Somchart et al., 2005).

\section{Effect of Milling}

\section{Factors affecting head rice yield}

India enjoys a wide range of agro climatic conditions. The climatic conditions with high humidity and temperature have detrimental effect on the milling yield of grains. The increase in temperature during the milling causes the thermal stress due to fluctuation in temperature from $30^{\circ} \mathrm{C}$ (grain temperature) to $45^{\circ} \mathrm{C}$ (after milling). This effect is increased manifolds when the ambient temperature varies from $40-50^{\circ} \mathrm{C}$ in summers. The changes in temperature of the grains have been correlated negatively with HRY.

The efficiency of milling is decided by its HRY and whiteness other than deciding its transaction price which is also dependent on shape, size and cleanliness of the rice 
(Conway, 1991). Head rice is capable of fetching two to three times more price than that of broken kernels. A number of studies have been focused on improving milling quality through plant breeding programs, improved cultural practices, optimization of harvesting and drying conditions (Abud et al., 2000; A-Bond et al., 2007; Dong et al., 2003; Gravois, 1998). Delay in harvest has been shown to reduce HRY due to low kernel moisture contents (Sajawan et al., 1990), optimum moisture content for seven US varieties to harvest varied from $16 \%$ to 21.5 $\%$ (d.b.) to achieve maximum HRY (Jodari and Linscombe, 1996). To reduce the occurrence of fissures and improve the milling characteristics research has been pursued on post-harvest management of rice along with optimising the conditions for harvesting and drying. Increase in the bulk surface temperature of the grain during milling due to abrasion/friction induces thermal stress, leading to crack generation and ultimately results in reduction in head rice yield (Debabandya and Satish, 2004).

The determination of milled rice quality parameters by image processing techniques will enable regular monitoring of milling operation in an objective manner, and thus allowing the operator to quickly react within a few minutes to changes in material properties. Digital image analysis was used to determine the head rice yield (HRY), three-dimensional features (length, projected area perimeter) were recorded from the milled samples. Characteristic Dimension Ratio (CDR) was computed which is defined as the ratio of the sum of a particular dimensional feature of all head rice kernels to that of all kernels comprising head and broken rice in the sample (Yadav and Jindal, 2001). The results showed that two-dimensional imaging of milled rice kernels could be used for making quantitative assessment of HRY and degree of milling for on-line monitoring and better control of the rice milling operation. Quality parameters like whiteness and HRY should be estimated from two dimensional image while the correlation mean gray level have been reported with the lipid concentration on the surface of rice kernels (Fant et al., 1994). It was hypothesized that the overall whiteness of milled rice could be estimated simply from the mean value of the gray level distribution obtained from the digitized image of the bulk sample. Digital image analysis has been used to estimate the area of the bran layer on the surface of rice kernels and correlated with the surface lipids concentration determined by chemical analysis (Liu et al., 1998).

Milling experiments were conducted by certain modifications in vertical mill plant where the optimal conditions were $15 \%$ moisture content, shaft speed of $900 \mathrm{~min}^{-1}$, emery stones of mesh size no. 50, zero outlet resistance and milling rate of $2 \cdot 3 \mathrm{t} \mathrm{h}^{-1}$ (Yan et al., 2005). The optimisation was based on the embryo adherence ratio, broken rice ratio, and whiteness of milled rice. White embryo rice is white rice with embryo, having valuable nutrients and fibre. The factors affecting the adherence of rice embryo include mill characteristics (Koh, 1993; Hosokawa et al., 1995).

\section{Effect of degree of milling (DOM) on rice quality}

The DOM of rice was cultivar dependent (Siebenmorgen et al., 2006). Most of the physical properties significantly affected DOM. Researchers have co-related the length and aspect ratio positively with DOM while the width, thickness and sphericity and bulk density showed negative co-relation with DOM (Sun and Siebenmorgen, 1993; Prom-uThai et al., 2007b). Surface area and true density had non-significant effect on the DOM at all milling stages (0-100s) (Liang et al., 2008). DOM affected the nutritional 
quality of milled rice grains. Previous studies have reported loss of selenium (Kunlun et al., $2009)$, loss of protein $(28.6 \%)$, total minerals (84.7\%) (Lamberts et al., 2007), iron (2484\%) (Prom-u-Thai et al., 2007a) with DOM.

\section{Effect of drying and tempering on milling of rice}

High yield of brokens is the major problems of the rice industry. The breakage of kernels during milling is caused due to stress cracks (fissures). Major factors responsible for fissuring are rice variety, management of post-harvest operations and drying conditions which include drying methodology and operating conditions (Ban, 1971; Bautista et al., 2000; Kunze, 1979; Kunze and Choudhury, 1972; Nguyen and Kunze, 1984; Sharma and Kunze, 1982; Cnossen and Siebenmorgen, 2000). The proportion of fissured kernels increases with the temperature and the evaporating capacity of the air (Bonazzi et al., 1997).

It is important to understand the changes caused during post-harvest handling of grains leading to formation of fissures to control and optimize drying conditions for maximizing milling quality. Fissures are caused due to rapid adsorption and desorption moisture during post handling operations (Kunze and Choudhury, 1972; Cnossen et al., 2003). During drying, the moisture evaporates from the surface of the grain which is followed by the diffusion of the moisture from the centre of the grain to the surface (Li et al., 1999). This causes compressive force in the outer layer and tensile force in the inner portion. When the compressive stresses at the grain surface exceed the tensile strength of its interior, the kernel will be fissured. A grain with a fissure is likely to break when the kernel is milled (Sharma and Kunze, 1982).

The quality of rough rice can be damaged if air with high evaporative capacity is used for drying, function of temperature and $\mathrm{RH}$ (Bonazzi et al., 1997). High drying temperatures, up to $80{ }^{\circ} \mathrm{C}$, can be used without affecting the processing quality of the rice provided that the $\mathrm{RH}$ of the air is high (Abud et al., 2000).

Post-drying tempering at high temperature $\left(60^{\circ} \mathrm{C}\right)$ resulted in greater moisture removals and drying time reductions up to $38 \%$ can be achieved. Percentage of fissured kernels was drastically reduced when drying was performed in two or three steps compared to drying in one step. Tempering at high temperature reduced the percentage of fissured kernels and enhanced HRY (Head Rice Yield). For attaining a moisture removal of six points without affecting the rough rice quality, drying in two stages with the post drying tempering period of $60^{\circ} \mathrm{C}$ gave the best results along with energy saving (Aquerreta $e t$ al., 2007).

A number of drying methods were applied to study the effects of drying conditions on parboiled rice viz. hot air drying, sun drying, super-heated steam, fluidised bed drying and vacuum drying. The drying temperature has a negative effect while the tempering time has a positive effect on HRY (Elbert et al., 2001). The browning index was mainly affected by the temperature of the air used for drying. It was recorded that pre-steaming time increased the HRY, degree of gelatinisation and pasting properties and decreased the white belly of partially par-boiled rice (Thanit et al., 2009).

Sutherland and Ghaly (1992), applied hot-air fluidization technique on paddy which comprised of soaking $\left(80^{\circ} \mathrm{C}\right.$ for $\left.5 \mathrm{~h}\right)$, presteaming $\left(102^{\circ} \mathrm{C}\right.$ for $\left.70 \mathrm{~s}\right)$, drying using fluidization technique with hot-air $\left(140^{\circ} \mathrm{C}\right.$ for $2 \mathrm{~min}$ ), tempering (30 $\mathrm{min})$ followed by ventilating at ambient air temperature until the final moisture content reached approximately $14-16 \%$ d.b. While studying the feasibility of paddy drying using hot-air 
fluidized bed it was found that the head rice yield was related to the final moisture content. An increase in the initial moisture content leads to increase in the head rice yield. The development of stresses inside the kernel due to rapid drop of moisture content in fluidized bed drying causes the reduction of head rice yield affecting the rice quality and low commercial value (Soponronnarit and Prachayawarakorn, 1994). To maximize the full kernel yield, the tempering stage was recommended after the first stage of drying for reducing moistures stresses (Steffe, 1979; Soponronnarit et al., 1999; Cnossen et al., 2003). Partial gelatinization was caused in pre-steamed rice which increases the strength of the grain thereby increasing its hardness as compared to that of the reference rice (Kato et al., 1983).

Superheated-steam drying has many plus points such as high drying rate and deodorization of products (Iyota et al., 2002). The moisture content after first-stage drying and tempering have a dominant effect on head-rice yield and operating time in reducing high-moisture contents to a safe level. It was suggested that steaming at $150^{\circ} \mathrm{C}$ for the first stage and the moisture content after first-stage drying should be not lower than $22.5 \%$ dry basis, with subsequent tempering for at least 25 minutes (Somchart et al., 2005).

A higher intermittent ratio or lower unit drying time caused lower percentage of fissured rice (Li et al., 1999). The kernels did not fissure immediately after drying so method could be developed to prevent $h$ the formation of fissures (Bautista et al., 2000). Tempering at temperature $45^{\circ} \mathrm{C}$ reduced the fissured kernel by $25 \%$ in comparison to storage at low temperatures (Nguyen and Kunze, 1984), tempering at $50^{\circ} \mathrm{C}$ reduced fissuring incidence by 32 to $50 \%$ compared to tempering at $20^{\circ} \mathrm{C}$ (Renjie et al., 2009), tempering at even higher temperature $\left(60^{\circ} \mathrm{C}\right)$ permitted faster drying time without affecting the rice quality (Cnossen and Siebenmorgen, 2000; Cnossen et al., 2003). Rate of open crack formation increased with decreasing the soaking temperature. Water diffusion into rice grains should be accelerated to prevent the formation of open cracks (Takuma et al., 2011). The effect of far-infrared (FIR) irradiation on drying and milling quality of paddy revealed that critical moisture content after the fluidized bed drying was around 23\% d.b. whereas incorporating with the FIR irradiation could continuously reduce the moisture content to $21 \%$ d.b. without affecting paddy head rice yield and whiteness (Naret et al., 2004).

Rice fissuring problem is more prevalent in drying with heated air at $60^{\circ} \mathrm{C}$ (Kunze, 1979; Sharma and Kunze, 1982). Fissuring in the kernels is caused due to the stresses developed due to moisture and temperature gradients developed during drying. After drying the causative factors are drying rate and storage relative humidity, where the percentage of fissured kernels increased with the increase in drying temperatures (Siebenmorgen et al., 2006; Kunze, 1979; Nguyen and Kunze, 1984; Sharma and Kunze, 1982; Yang et al., 2002). Tempering allows moisture diffusion from the interior to the external surface of the grain kernels to decrease the moisture gradients and then reduces the rice fissuring (Iguaz et al., 2006; Schluterman and Siebenmorgen, 2007).

Proper tempering with high temperatures can reduce the kernel fissuring in severe drying conditions and enhance the HRY independently of the number of drying steps involved (Aquerreta et al., 2007; Perdon et $a l ., 2007)$. The number of fissured kernels reduced by about $25 \%$ for rice (variety Brazos) dried and stored at $60^{\circ} \mathrm{C}$ and $45^{\circ} \mathrm{C}$ respectively compared to that stored at $10^{\circ} \mathrm{C}$ (Nguyen and Kunze, 1984). 
Aqueretta et al., 2007 reported that the percentage of fissured kernels was reduced and HRY enhanced on tempering at higher temperature irrespective of the number of drying steps. A hypothesis was developed by Sharma and Kunz, 1982 to explain rice kernel fissuring during drying and tempering by incorporating the glass transition temperature concept. It is considered that the state transition of starch occurred in the temperature range typically used in rice drying and tempering processes plays an important role in rice kernel fissuring (Perdon et al., 2000; Siebenmorgan et al., 2004). The differences in amylose and protein contents affected the thermal properties due to their influence on the degree of crystallinity (Perdon et al., 2000).

Fissured kernels are found both in artificial as well as natural drying in the field after harvest (Kunze and Calderwood, 1985). Moisture gradients developed in the rice kernels during drying cause differential stress inside the kernel and are a reason for later fissuring (Kunze, 1979). The number of fissured kernels can be reduced by doing intermittent drying, with tempering periods inserted between drying cycles as tempering shortens the total in-dryer time and helps prevent rice fissuring and breakage, giving a decrease of $20 \%$ in fissures compared to continuous drying by equalising the moisture concentration trends and decreasing the size of moisture gradients (Li et al., 1999; Iguaz et al., 2006).

Modulus of elasticity, bending strength, and fracture energy of the sound brown rice kernels increased with longer drying. Mechanical properties measured on the sound kernels at different drying durations would not be affected by the loss of the sound kernels to fissured or broken kernels (Zhang et al., 2005). The finite element simulation studies of internal stresses of rice by Jia et al., 2002 revealed that tensile stresses showed a sharp increase in the beginning of drying, peaked shortly after drying, and then dropped gradually thereafter. For understanding the fissuring problem it is pertinent to know the mechanical properties of rice kernels which include the tensile strength (Kunze and Choudhury, 1976; Arora et al., 1973), compressive strength (Prasad and Gupta, 1973) and bending strength (Nguyen and Kunze, 1984; Bamrungwong et al., 1987; Chattopadhyay et al., 1979; Lu and Siebenmorgen, 1995). Fissures might develop in rice kernels during or after the drying process if the tempering is omitted after drying when the rice kernels go from rubbery to glassy transition state. Tempering has been shown to be an effective way to preserve HRY that would otherwise be reduced for an extended drying duration (Cnossen and Siebenmorgen, 2000; Steffe and Singh, 1980). Fissures could be initiated and/or propagated during the drying (desorptive) process.

An increase in the temperature and evaporating capacity of air augmented the percentage of fissured kernels whereas intermediate and final tempering improved final rice quality by decreasing the number of fissured kernels and thereby increasing head rice yield (Iguaz et al., 2006).

Glass transition temperature of a rice kernel is a function of moisture content. As the kernel temperature passed through its glass transition temperature $\left(T_{\mathrm{g}}\right)$ there is a change in expansion coefficient, specific volume and diffusivity of the rice kernel (Perdon, 1999). If tempering after drying is performed under $T_{\mathrm{g}}$, then a different expansion coefficient is created in the two parts of the kernel, the outer layer is in the glassy state while the centre is still in the rubbery state which cause kernel fissuring Cnossen et al., 2003.

Tempering temperatures of $60^{\circ} \mathrm{C}$ followed high temperatures up to $80^{\circ} \mathrm{C}$ for drying can save time without diminishing rice quality 
(Cnossen et al., 2003; Iguaz et al., 2006). A decrease in the drying temperature and increase in tempering time was found to increase the HRY between $68 \%$ and $74 \%$ depending on the operating conditions. German et al., 2002 inferred that having a tempering time at $16 \%$ moisture content between a two-steps drying gives satisfactory rice yield with acceptable browning index for drying temperatures of $70^{\circ} \mathrm{C}$ or below (German et al., 2000).

The removal of large amount of moisture from parboiled rice requires multiple-stage drying interspersed with as it promotes moisture equilibration in rice and considerably reduces breakage during milling (Bhattacharya and Swamy, 1967). The moisture content of the grain influences its mechanical properties (Yang et al., 2003; Zoerb, 1958) whereas the grain temperature variation affects the coefficient of thermal expansion and other physical properties (Ekstrom et al., 1966). The greatest MC gradient existed in a direction perpendicular to the long axis of rice kernels and in the middle section of the longitudinal span of a kernel (Chen et al., 1999; Sarker et al., 1996; Yang et al., 2000).

Artificial drying immediately after harvesting is one of the main causes of kernel fissures. Virtually invisible fissures lead to high breakage ratios during milling. Head rice yield is not affected by high drying temperatures if evaporating capacity remains low (Abud et al., 2000). Drying paddy by superheated steam increased the HRY as it promoted starch gelatinization than that which is dried by hot air but the higher degree of Maillard's reaction especially during the first few minutes of drying resulted in lower values of whiteness of paddy. But little difference was noted difference between the percentage of white belly of paddy dried by superheated steam and hot air (Wathanyoo et al., 2004). Higher drying air temperature results in a higher grain temperature and longer tempering time leads to partial gelatinization of starch granules inside paddy affecting the grain qualities in a similar way to parboiled rice (Inprasit and Noomhorm, 2001). Fluidized bed drying parameters affecting the various properties of paddy are moisture content, drying air temperature and bed thickness (Sutherland and Ghaly, 1992).

The rice drying industry employs heated air in different dryer designs. A temperature of 45$78^{\circ} \mathrm{C}$ is used in column and cross flow dryers whereas some multi stage dryers operate at temperatures as high as $80-200^{\circ} \mathrm{C}$. These high temperatures are the main cause of kernel fissuring and breakage during milling (Inprasit and Noomhorm, 2001; Calderwood, 1975; Hogan and Karon, 1955). As high temperature drying establishes a MC gradient between the surface and the centre of the kernel due to evaporation from the outer layers of the kernel (Siebenmorgan et al., 2004). Air with high evaporative capacity is shown to adversely affect the rough rice quality (Bonazzi et al., 1997). Kunze and Calderwood, 1985 inferred that it is the drying rate rather than the drying air temperature which determines the quality of rice.

The MC gradient results in tensile and compressive stresses within the kernel, which if sufficiently large, provoke kernel fissuring and breakage. Tempering thus results in a more uniform moisture distribution within the kernel by facilitating moisture diffusion from the core to the surface (Cihan and Ece, 2001).

Cihen and Ece, 2001 found that a certain amount of moisture can be quickly removed at a higher temperature $\left(60^{\circ} \mathrm{C}\right)$ in a rubbery state, or above the glass transition temperature, without significantly lowering the head rice yield. A high heating rate and 
energy efficiency are achieved by IR radiation heating where (Das et al., 2004b) medium and far IR sources, with wavelengths of 2 $100 \mu \mathrm{m}$, have been investigated for drying agricultural products (Arinze et al., 1987; Nindo et al., 1995) and maximum absorption of IR radiation by medium grain rough rice occurred at a wavelength of $2.9 \mu \mathrm{m}$ as reported by Bekki, 1991. Mixing is recommended to achieve uniform heating of the rice in thick bed to overcome the limited penetration capability of IR (Nindo et al., 1995). Rapid cooling using forced air is not conducive as it removes considerable amount of moisture creating significant moisture and temperature gradients causing fissures (Kunze and Choudhury, 1972). The differences in the thermo mechanical properties of the starch at different stages would generate stresses and fissures, resulting in breakage during milling and a lower rice milling quality (Perdon et al., 2007; Siebenmorgan et al., 2004). Therefore, controlled slow cooling will be very important for high temperature rice drying.

\section{Parameters affecting milling quality of rice}

Rice kernel breakage during the milling process is affected by different parameters such as paddy harvesting conditions, paddy drying, physical properties of paddy kernels, environmental conditions, and type and quality of milling system components. Increase in the removal of bran layer is directly correlated with the kernel whiteness (Champagne et al., 1996; Park et al., 2001). Rice breakage was mostly due to mechanical stresses rather than thermal stresses (Matthews et al., 1970). The moisture of paddy has a significant effect on the milling system yield which showed an increase by $0.7-3 \%$ on $1 \%$ reduction of paddy moisture in the range of 10-14\% (Pominski et al., 1961). The least rice breakage was achieved on milling paddy at a moisture content of 12-14 $\%$ (w.b.) using three abrasive whiteners in series and one friction whitener as polisher (Afzalinia et al., 2002). The method of harvesting also influenced the rice breakage during milling when the breakage was 5\% more of sample harvested by combine rather than that which were manually harvested.

Paddy moisture content for milling process of 12 to $14 \%$ wet basis (w.b.) and using three abrasive whiteners in series and one friction whitener as a polisher had the least rice breakage (Afzalinia et al., 2002). Paddy moisture content had significant effect on milling system yield so that for $1 \%$ reduction of paddy moisture in the range of 10 to $14 \%$, performance of milling system increased by 0.7 to $3 \%$ (Pominski et al., 1961).

On evaluated the effect of harvesting method on rice breakage during the milling process it was found that rice breakage of samples that had been harvested by combine was $5 \%$ more than that of the manually harvested samples (Matthews and Spadaro, 1975). Moreover, rice breakage during the milling process increased with the decreasing kernel diameter (Matthews and Spadaro, 1976) and also with the increasing paddy moisture content in the range of 12 to $16 \%$ (Dilday, 1987). To have a high quality milling process with reasonable rice breakage, paddy must be harvested at the optimum moisture content and at the suitable stage of maturity (Luh, 1991).

Long and tiny rice kernels were more susceptible to breakage during the milling process (Clement and Seguy, 1994). Paddy drying conditions affected the rice breakage during the milling process so that rice breakage rapidly increased with the decreasing moisture content of paddy drying air (Peuty et al., 1994). The difference between paddy temperature and milling environment temperature decreased the performance of rice milling system; relative humidity of milling environment had 
significant effect on milling system yield (Autrey et al., 1995).

\section{Quality as affected by rice grain properties}

The inherent properties of rice and grain determine the quality of the milled rice. The amylose content in endosperm of non-waxy rice is reduced by an increase in the environment temperature (Asaoka et al., 1985). Amylose content has positive correlation with textural properties and solid loss in gruel leading to hard texture and less cooking time (Singh et al., 2005).

The knowledge of the physical and mechanical properties of the agricultural products is of fundamental importance for the correct storage procedure and for design, dimensioning, manufacturing and operating different equipment used in post harvesting main processing operations of these products (Silva and Corrêa, 2000).

All textural parameters showed a significant correlation with each other and had a positive correlation with amylose and negative correlation with cooking time. Amylose content was correlated positively with the solids loss in the gruel and all the textural parameters. The cultivars with high amylose content were observed to have a hard texture and less cooking time (Singh et. al. 2005). The higher environment temperature decreased amylose content in endosperm of non-waxy rice (Asaoka et. al 1985). A study revealed that no significant difference between the tensile strengths along the short and the long axes of the grain was observed, from which it follows that there is no significant anisotropy in the two measured directions (Kamst et al., 1999). The Young's moduli from the diametral compression experiments and from the uniaxial compression measurements are not significantly different.
Thermal conductivity, specific heat and thermal diffusivity are three important thermal properties to the quantitative analysis of a drying process. At temperatures around $53^{\circ} \mathrm{C}$, the rice variety Calora incurred a rapid increase in the percentage of broken kernels, and it kernels exhibited a marked increase in the rate of thermal expansion. The thermal conductivity of rough rice increased with increasing moisture content. It was found that the thermal conductivity changed little below and increased considerably above the glass transition temperature (Yang et al., 2003).

An investigation reported that the bulk density of all varieties increases with rice grain processing. This increasing could go up to $51 \%$ and the varieties differ statistically among them. In general the specific gravity of the rice grains is not influenced by the processing or by the varieties. The porosity of the bulk rice grains is affected by the processing, being the higher for rough rice and the lower for milled rice. The difference goes up to $26 \%$. The external static and dynamic friction coefficients decrease with processing in all type of wall materials and varieties, the static friction coefficient being more affected by varieties than the dynamic friction coefficient. The higher friction coefficients are from wood surface and the lower ones from steel surface (Corrêa et al., 2007).

Many studies shows that the moisture absorption by rice kernels as well as solid loss during cooking vary among different rice varieties usually characterized by their physicochemical properties such as amylose content, gel consistency, alkali spreading value or gelatinization temperature and protein content. For example, the water uptake rates were inversely related to the amylose content of three rice varieties under a study (Metcalf and Lund 1985). High protein rice required more water and longer time to 
cook (Husain 1981). High amylose rice has higher capacity to absorb moisture during cooking. The moisture absorption by cooked rice kernels with cooking duration could be best expressed by a modified exponential relationship for all rice varieties. The trends of moisture absorption during cooking were different among selected varieties manifested by their physicochemical properties, namely, amylase content (AC), alkali spreading value (AS), protein content (PC) and gel consistency (GC). Thus, the water uptake of milled rice during cooking in excess water can be predicted from its physicochemical properties (Yadav and Jindal 2007).

\section{Modelling}

A model is an intellectual tool which represents an abstract of a system or a process using mathematical concepts and languages. Modelling involves recording observations, its analyses (model fitting) and based on these results, predicting the behaviour of a particular process or parameter in the future. Different models to predict the drying behaviour, water absorption trend etc have been evaluated in rice processing.

A simple modelling framework was devised to study and analyse equilibrium moisture data in foods based on molecular thermodynamics, providing useful physical insight on the nature of the EMC in foods (Vasquez et al., 2011). The favourable results suggested its application for further analysis of EMC in foods.

A useful mathematical model to develop a rewetting method for brown rice by using film packaging technique, design was established. Packaging of rice with polymeric film mainly aimed at inhibiting change in moisture content of the rice was established. The proposed model was based on the water vapour balance in the film package containing brown rice. The predicted $\mathrm{RH}$ and rice moisture content inside a package were in close association with experimental readings of re-wetting experiments (Genkawa et al., 2008).

Tanakaa et al., 2010 developed a mathematical model to predict a moisture content profile during the thick layer rewetting process of brown rice unpackaged and packaged with low density polyethylene (LDPE) and polybutylene terephthalate (PBT) films. It was concluded that the proposed rewetting model could successfully describe the thick layer re-wetting of brown rice under the experimental conditions.

Courtois et al., 2001 concluded that the rice kernel is modelled as a two water compartment system and as a whole concerning heat and quality. The external transfers are governed by Fick and Fourier laws. The compartmental approach is mainly used to render the internal resistance in the most efficient way on the computer. Results have shown a robust behaviour for such a non-linear system. Soaking is a pre-treatment operation usually done before cooking of milled rice to provide desired softness and texture in the final cooked rice, which plays a vital role in deciding consumer's preference.

The prediction models developed for the drying rate constant using a power law model and an Arrhenius model had higher coefficient of determination 0.94 and 0.94 indicating both the models fit adequately. Drying time was dependent mostly on drying air temperature followed by grain depth and air velocity (Rao et al., 2007).

With increase in air temperature the heat transfer coefficient during convective air drying increased. The milling quality improved with increase in air velocity and decrease in grain bed depth and air 
temperature. The head yield in convective air drying was mostly affected by grain bed depth followed by drying air temperature. Drying air velocity had little impact on the head yield (Rao et al., 2007).

Cooling the grain until a safe temperature is reached, can inhibit insect and mould activity and minimise the use of chemical treatments. An aeration system can also prevent deterioration by reducing the temperature gradients throughout the grain bulk which may cause moisture migration and pockets of mouldy grain (Metzger et al., 1983). As for the drying process, the proportion of fissured kernels increases with the temperature and the evaporating capacity of the air (Bonazzi et al., 1997; Aguerre et al., 1986). A mathematical model based on dynamic heat and mass balances was developed to stimulate the evolution of grain and air temperature and moisture content in a rough rice storage bin with forced cool air ventilation. The model and parameters used in the model are applicable for temperature prediction purposes. Using the model it is possible to predict the evolution of grain temperature and moisture and the time needed to cool the stored grain under different ventilation conditions (Iguaz et al., 2004). HRY and whiteness could be successfully modelled during milling operation in relation to the physicochemical properties of rice. Reduction in HRY was a power function of the milling duration with $R^{2}$ of fitting ranging from 0.974 to 0.997 and root mean square error (RMSE) values of below $1 \%$ among the selected varieties (Husain et al., 1987).

Modified GAB model was more appropriated to predict desorption equilibrium moisture content of rough rice for the range of temperatures and water activities studied. Modified Chung-Pfost model and modified Henderson model gave an acceptable fitting, while modified Halsey model and modified
Oswin model did not seem appropriate for the description of the desorption moisture isotherms of rough rice at drying temperatures (Iguaz et al., 2006).

In a simulation, the flow restrictions were found in the processes for separating brown rice and for sorting coloured rice and needed an increase in the hourly capacities of the brown rice separator and the rice colour sorter. As the automated rice mill plant was described by the developed model, it could be used for designing and improving rice mill plants. There were no flow restrictions in the processes of destoning, hulling, milling, polishing, but there was a severe flow restriction in the colour sorting process due to high sensitivity and low feed-rate of a colour sorter in the simulation (Chung and Lee, 2003).

To be able to minimize cracks and breakage, a predictive model of the stresses and deformations in the material during drying is necessary. As the fissures in rice kernels are due to a tension failure, the tensile strength must be known to be able to predict the cracking of the grains. It is known that the deformation rate has an influence on the mechanical properties (Chattopadyay and Hamann, 1994).

It is forecasted that the demand of rice is expected to increase to 880 million tons by 2025, and to meet this demand good agricultural and milling practices are needed to minimize the losses in post-harvest management. The post-harvest losses are attributed to a combination of factors during production and post-production operations. Several efforts are being done in order to maintain the grain quality of this crop in its different processing operations. Percentage of HRY is the most important parameter in the milling. The grain behavior is dependent on moisture content during the harvest, drying 
mechanism, moisture content present during milling, milling conditions i.e. type of mill used, speed, temperature gradient, degree of polishing, variety of paddy, pretreatments given before milling etc. The major problem in milling is of grain breakage thus reducing the HRY, caused due to development of compressive and tensile forces in the grain. These stresses are mainly caused due to the thermal gradient developed during milling. To minimize the temperature gradient, modification in the existing machinery is required. HRY is better in parboiled rice due to gelatinization of starch. Parboiled rice are able to bear the frictional forces to higher value thus yielding better head rice yield but the cost of the machinery affects the economics of operation. Thus, the rice postharvest system requires improvement in the use of resources for research and development.

\section{References}

Abe, T., and Afzal, T.M. 1998. Heat and mass transfer characteristics of barley during far infrared radiation drying. In: Proceedings of $2^{\text {nd }}$ international workshop on "Control applications in post-harvest and processing technology" CAPPT'98, Budapest, Hungary.

A-Bond, J., and Bollich, P. K. 2007. Effect of preharvest desiccants on rice yield and quality. Crop Protection, 26: 490-494.

Abrol, C. M., 1983. Studies on parameters for parboiling of broken rice. Unpublished $\mathrm{M}$. Tech. Thesis, IIT, Kharagpur.

Abud, A., Courtois F., Bonazzi, C., and Bimbenet, J. J. 2000. A compartmental model of thinlayer drying kinetics of rough rice. Drying Tech., 18: 1389-1414.

Adhikaritanayaka, T. B., and Noomhorm, A. 1998. Effect of continuous steaming on parboiled rice quality. J. Food Eng., 36: 135143.

Afzal, T.M., and Abe, T. 1997. Combined convection and far-infrared radiation drying of rough rice. ASAE Paper No. 9760972. St. Joseph MI.

Afzalinia, S., Shaker, M. and Zare, E. 2002.
Comparison of different rice milling methods. Presentation "The society for Engineering in Agricultural, Food and Biological systems". Paper No: MBSK 02- 214.

Aguerre, R., Suárez, C. and Viollaz, P.E. 1986. Effect of drying on the quality of milled rice. J. Food Tech., 21: 75-80.

Aquerreta, J., AIguaz, A., Arroqui, C. and Virseda, P. 2007. Effect of high temperature intermittent drying and tempering on rough rice quality. J. Food Engg, 80: 611-618.

Arinze, A., Schoenau, J. and Bigsby, W. 1987. Determination of solar energy absorption and thermal radiative properties of some agricultural products. Transactions of ASAE, 30: 259-265.

Arora, V. K., Henderson, S. M. and Burkhardt, T. H. 1973. Rice drying cracking versus thermal and mechanical properties. Transactions of the ASAE, 16: 320-327.

Asaoka, M., Okuno, K. and Fuwa, H. 1985. Effect of environmental temperature at the milky state on amylose content and fine structure of amylopectin of waxy and non-waxy endosperm starches of rice Oryza sativa L. Agric. Biol. Chem., 49: 373-379.

Autrey, H. S., Grigorief, W. W., Altschul, A. M. and Hogan, J. T. 1995. Effect of milling conditions on breakage of rice grains. $J$. Agric. Food Chem., 3: 593-599.

Bamrungwong, S., Satake, T., Vargas, D. and Yoshizaki, S. 1987. Fundamental studies on mechanical properties of long grain rice varieties: I. Compressive properties of long grain rice. Jap. J. Trop. Agri., 31: 232-240.

Ban, T., 1971. Rice cracking in high rate drying. Jap. Agri. Res. Quart., 6:113-116.

Bautista, R. C., Siebenmorgen, T. J. and Cnossen, A. G. 2000. Fissure formation characterization in rice kernels using video microscopy, In Proceedings of the 2000 International Drying Symposium, Noordwijkerhout, and The Netherlands.

Bekki, E., 1991. Rough rice drying with a farinfrared panel heater. J. Jap. Soc. Agric. Mach., 53, 55-63.

Bello, M., Baeza, R. and Tolaba, M. P. 2004. Quality characteristics of milled and cooked rice affected by hydrothermal treatment. $J$. Food Engg, 72: 124-133.

Bhattacharya, K. R., 1985. Parboiling of rice. In: 
Rice: Chemistry and Technology, Juliano, B. O., Eds., American Association of Cereal Chemists, St Paul, USA.

Bhattacharya, K.R., Ali, S.Z. and Indudhara Swamy, Y.M. 1971. Commercial drying of parboiled paddy with LSU dryers. J. Food Sci. Technol., 8: 57-63.

Bhattacharya, K.R., and Indudhara Swamy, Y.M. 1967. Conditions of drying parboiled paddy for optimum milling quality. Cereal Chem., 44: 592-600.

Bilowicka, E., 1960. Research concerning the drying of small seeds by infrared radiation, International drying conference, Institute of Mechanization and Electrification of Agriculture, Warsaw, Poland.

Bonazzi, M.A., Peuty, D. and Themelin, A. 1997. Influence of drying conditions on the processing quality of rough rice. Drying Technol., 15: 1141-1157.

Calderwood, D. L., 1975. Rough rice paddy drying methods in the United States. Tropical Stored Products Info, 30: 13-22.

Champagne, E. T., Richard, O. A., Bett, K. L., Grimm, C. C., Vinyard, B. T. and Webb, B. D. 1996. Quality evaluation of US medium grain rice using Japanese taste analyzer. Cereal Chem., 73: 290-294.

Chattopadhyay, P. K., Hammerle, J. R. and Hamann, D. D. 1979. Time, temperature, and moisture effects on the failure strength of rice. Cereal Foods World, 24: 514-516.

Chattopadyay, P.K., and Hamann, D.D. 1994. The rheological properties of rice grain. J. Food Proc. Eng., 17:1-17.

Chen, H., Siebenmorgen, T. J. and Yang, W. 1999. Finite element simulation to relate head rice yield reduction during drying to internal kernel moisture gradient and rice state transition. ASAE Paper No. 99-6156.

Chung, J.H., and Lee, Y.B. 2001. Simulation of a Rice Mill Process. Bios. Eng. 86: 145-150.

Cihan, A., and Ece, M. C. 2001. Liquid diffusion model for intermittent drying of rough rice. $J$. Food Engg, 49: 327-331.

Clement, G., and Seguy J. I. 1994.Behaviour of rice during processing. Agric Develop, 16: 38-46.

Cnossen, A. G., Jiménez, M. J and Siebenmorgen, T. J. 2003. Rice fissuring response to high drying and tempering temperatures. J. Food
Engg, 59: 61-69.

Cnossen, A.G., and Siebenmorgen, T.J. 2000. The glass transition temperature concept in rice drying and tempering effect on milling quality. Transactions of the ASAE, 23: 16611667.

Conway, J. A., Sidik, M. and Halid, H. 1991. Quality/value relationships in milled rice stored in conventional warehouses in Indonesia. In: Proceedings of the fourteenth ASEAN seminar on grain postharvest technology, 5-8 November, pp. 55-82. Manila, Philippines.

Corrêa, P.C., Schwanz da Silva, F., Jarenb, C., Afonso Júnior, P.C. and Aranab, I. 2007. Physical and mechanical properties in rice processing. J. Food Engg, 79: 137-142.

Courtois, F., Abud, A. M., Bonazzi, C., Meot, J.M. and Trystram, G. 2001 Modelling and control of a mixed-flow rice dryer with emphasis on breakage quality. J. Food. Engg, 49: 303-309.

Das, I., Das, S. K. and Bal, S. 2004 a. Determination of mixing index of paddy grains under vibrating conditions. J. Food Proc. Engg, 26: 121-133.

Das, I., Das, S.K. and Bal, S. 2004 b. Specific energy and quality aspects of infrared IR dried parboiled rice. J. Food Engg, 62: 129133.

Debabandya, M., and Satish, B. 2004. Wear of rice in an abrasive milling operation, part ii: prediction of bulk temperature rise. Bios. Engg, 89: 101-108

Dilday, R.H., 1987. Influence of thresher cylinder speed and grain moisture at harvest on milling yield of rice. Arkansas Academy of Science. 41: 35-37.

Dong, Y., Tsuzuki, E., Dongzhi, L., Kamiunten, H., Terao, H. and Matsuo, M. 2003. Molecular genetic mapping of quantitative trait loci for milling quality in rice (Oryza sativa L.). J. Cereal Sci., 40: 109-114.

Ekstrom, G. A., Lijedahl, J. B. and Peart, R. M. 1966. Thermal expansion and tensile properties of corn kernels and their relationship to cracking during drying. Transactions of the ASAE, 9: 556-561.

Elbert. G., Tolaba, M. P. and Suarez, C.2001. Effect of drying conditions on head rice yield and browning index of parboiled rice. J. Food 
Engg, 47: 37-41.

Fan, J., Marks, B. P., Daniels, M. J. and Siebenmorgen, T. J. 1999. Effect of postharvest operations in the gelatinization and retrogradation properties of long-grain rice. Transactions of the ASAE, 42: 727-731.

Fant, E., Casady, W., Goh, D. and Siebenmorgen, T. 1994. Grey-scale intensity as a potential for degree of rice milling. J. Agric. Engg. Res., 58, 89-97.

FAO 2014. www.fao.org/3/a-i4294e.pdf

FAO, 2004. http://www.fao.org/rice2004/en/fsheet/factsheet8.pdf

Genkawa, T., Uchino, T., Miyamoto, S., Inoue, A., Ide, Y., Tanaka, F., and Hamanaka, D. 2008. Development of mathematical model for simulating moisture content during the rewetting of brown rice stored in film packaging. Bios. Engg, 101: 445-451.

German, E., Marcela, P. T., and Constantino, S. 2000. Effects of drying conditions on head rice yield and browning index of parboiled rice. J. Food Engg, 47: 37-41.

Ginzburg, A. S., 1969. Application of infrared radiation in food processing. Leonard Hill, London.

Gravois, K. A., 1998. Optimizing selection for rough rice yield, head rice, and total milled rice. Euphytica, 101: 151-156.

Heinemann, R. J. B., Fagundes, P. L., Pinto, E. A., Penteado, U. M., and Lanfer-Marquez U. M. 2005. Comparative study of nutrient composition of commercial brown, parboiled and milled rice from Brazil. J. Food Comp. Anal., 18: 287-296.

Hogan, J. T., and Karon, M. L. 1955. Hygroscopic equilibria of rough rice at elevated temperatures. Agric. Food Chem., 3: 588-860.

Hosokawa, A., Ban, T., Yokosawa, I., Yanase, H., and Chikubu, S. 1995. Rice Post-Harvest Technology, The Food Agency, Ministry of Agriculture, Forestry and Fisheries, Japan, pp. 351-379.

Husain, A.N., Hwa, C.Y., and Ahmad, L. 1981. In Rice quality in the Malaysian context, Proceedings of the national rice conference of research for the rice farmers. Malaysian Agricultural Research and Development Institute, Malaysia.

Iguaz, A., Arroqui, C., Esnoz A., and Vírseda, P. 2004. Modelling and Simulation of Heat
Transfer in Stored Rough Rice with Aeration. Bios. Engg, 89: 69-77.

Iguaz, A., Rodríguez, M., and Vírseda, P. 2006. Influence of handling and processing of rough rice on fissures and head rice yields. J. Food Engg, 77: 803-809.

Inprasit, C., Noomhorm, A. 2001. Effect of drying air temperature and grain temperature of different types of dryer operation on rice quality. Drying Technol., 19: 389-404.

IRC, 2002. Proceedings of the 20th Session of the International Rice Commission Bangkok, Thailand, 23-26 July 2002. http://www.fao.org/docrep/006/y4751e/y4751 e00.htm

Islam, M. R., Shimizu, N., and Kimura, T. 2004. Energy requirement in parboiled and its relationship to some important quality indicators. J. Food Engg, 63: 433-439.

Itani, T., Tamaki, M., Arai, E., and Horino, T. 2002. Distribution of amylose, nitrogen, and minerals in rice kernels with various characters. J. Agric. Food Chem., 50: 53265332.

Iyota, H., Nishimura, N., Nomura, T., Konishi, Y., and Yoshida, K. 2002. Effect of initial steam condensation on color changes of potatoes during drying in superheated steam. In: Proceedings of the 13th International Drying Symposium, pp. 1352-1359. Beijing, China.

Jia, C. C., Yang, W., Siebenmorgen, T. J., Bautista, R. C., and Cnossen, A. G. 2002. A study of rice fissuring by finite element simulation of internal stresses combined with high-speed microscopy imaging of fissure appearance. Transactions of the ASAE, 45:741-749.

Jodari, F., and Linscombe, S. D. 1996. Grain fissuring and milling yields of rice cultivars as influenced by environmental conditions. Crop Sci., 36:1496-1502.

Juliano, B. O., 1985. Rice properties and processing. Food Reviews Intl., 1: 432-445.

Kamst, G.F., Vasseur, J., Bonazzi C., and Bimbenet J.J. 1999. A new method for the measurement of the tensile strength of rice grains by using the diametral compression test. J. Food Engg, 40: 227-232.

Kar, N., Jain, R. K., and Srivastav, P. P. 1999. Parboiling of dehusked rice. J. Food Engg, 39: 17-22. 
Kato H., Ohta, T., Tsugita, T., Y. and Hosaka, Y. 1983. Effect of parboiling on texture and flavor components of cooked rice. J. Agric. Food Chem., 31: 818-823.

Kimura, T., Bhattacharya, K. R. and Ali, S. Z. 1993. Discoloration characteristics of rice during parboiling I: Effect of processing conditions on the color intensity of parboiled rice. J. Soc. Agric. Struc. 24: 23-30.

Koh, H.K., 1993. Post-harvest Processing Machinery, Hyangmun. Publisher, Korea.

Kunlun, L., Xiaohong, C., Qingyun, B., Huanbin, W., and Zhenxin G. 2009. Relationships between physical properties of brown rice and degree of milling and loss of selenium. $J$. Food Engg, 94: 69-74.

Kunze, O. R., 1979. Fissuring of the rice grain after heated air drying. Transactions of the ASAE, 22:1197-1202.

Kunze, O. R., and Choudhury, M. S. U. 1972. Moisture adsorption related to the tensile strength of rice. Cereal Chem., 49:684-696.

Kunze, O.R., and Calderwood, D. L. 1985. Rough rice drying. In: Rice: chemistry and technology, pp. 163-233. Juliano, B.O. Eds., the American Association of Cereal Chemists, Inc., St. Paul, MN.

Lamberts. L., De Bie, E., Vandeputte, G. E., Veraverbeke, W.S., Derycke, V., De Man, W., and Delcour, J.A. 2007. Effect of milling on colour and nutritional properties of rice. Food Chem., 100: 1496-1503.

Li, Y. B., Cao, C. W., Yu, Q. L., and Zhong, Q. X. 1999. Study on rough rice fissuring during intermittent drying. Drying Technol., 17: 1779-1793.

Liang, J., Li, Z., Tsuji, K., Nakano, K., Nout, M. J. R., and Hamer, R. J. 2008. Milling characteristics and distribution of phytic acid and zinc in long-, medium- and short-grain rice. J. Cereal Sci., 48: 83-91.

Liu, W., Tao, Y., Siebenmorgen, T. J., and Chen, H. 1998. Digital image analysis method for rapid measurement of degree of milling of rice. Cereal Chem., 75:380-385.

Lu, R., and Siebenmorgen, T. J. 1995. Correlation of HRY to selected physical and mechanical properties of rice kernels. Transactions of the ASAE, 38: 889-894.

Luh, B. S., 1991. Rice. I. Production. 2nd Ed. New York, USA: Van Nostrand Reinhold.
Marchezan, E., 1991. Grãos inteiros em arroz Whole rice kernels in rice. Lavoura Arrozeira, Porto Alegre, Brazil, 44:3-8.

Masamure, A., Sado, H., Hoda, T., Shimizu, M., Nabetani, H., and Nakajima, M. 1998. Drying of potato by far infrared radiation. Nippon Shokuhin Kogyo Gakkaishi. 35: 309-314.

Matthews, J., Abadie, T. J., Deobald, H. J., and Freeman, C. C. 1970. Relation between head rice yields and defective kernels in rough rice. Rice J., 73: 6-12.

Matthews, J., and Spadaro, J. J. 1975. Rice breakage during combine harvesting. Rice J., 78: 59-63.

Matthews, J., and Spadaro, J. J. 1976. Breakage of long grain rice in relation to kernel thickness. Cereal Chem., 53:13-19.

Metcalf, S.L., and Lund, D.B. 1985. Factors affecting water uptake in milled rice. J. Food Sci., 50:1676-1679.

Metzger, J.F., and Muir, W.E. 1983. Computer model of two dimensional conduction and forced convection in stored grain. Can. Agric. Engg., 25: 119-125.

Naret, M., Adisak, N., Thanid, M., and Somchart, S. 2004. Influence of FIR irradiation on paddy moisture reduction and milling quality after fluidized bed drying. J. Food Engg, 65: 293-301.

Nguyen, C.N., and Kunze, O. R. 1984. Fissures related to post-drying treatments in rough rice. Cereal Chem., 61: 63-68.

Nindo, C.I., Kudo, Y., and Bekki, E. 1995. Test model for studying sum drying of rough rice using far-infrared radiation. Drying Technol., 13:225-238.

Park, J. K., Kim, S. S., and Kim, K. O. 2001. Effect of milling ratio on sensory properties of cooked and on physicochemical properties of milled and cooked rice. Cereal Chem., 78:151-156.

Pederson, B., Knudsen, K. E., and Eggum, B. O. 1989. Nutritional value of cereal products with emphasis on the effect of milling. World Rev Nutr and Dietet, 60: 1-91.

Perdon, A. A., 1999. Amorphous state transition in rice during the drying process. Ph. D. dissertation Fayetteville, Ark.: Department of Food Science, University of Arkansas.

Perdon, A. A., Siebenmorgen, T. J., and Mauromoustakos, A. 2000. Glassy state 
transition and rice drying: development of a brown rice state diagram. Cereal Chem., 77: 708-713.

Peuty, M.A., Themelin, A., Bonazzi, C., Arnaud, G., Salokhe, V.M., and Singh G. 1994. Paddy drying quality improvement by process optimization. In: Proceeding I International Agricultural Engineering Conference. 6-9 Dec, pp. 298-304. Bangkok, Thailand.

Pillaiyar, P., and Mohandass, R. 1981. Hardness and colour in parboiled rices produced at low and high temperatures. J. Food Sci. Technol., 18: 7-9.

Pominski, J., Wasserman, T., Schultz, E. F. Jr., and Spadaro, J. J. 1961. Increasing laboratory head and total yield of rough rice by milling at low moisture levels. Rice J., 64: 11-15.

Prasad, S., and Gupta, C. P. 1973. Behavior of paddy grain under quasi-static compressive loading. Transactions of the ASAE, 16: 328330.

Prom-u-Thai, C., Fukai, S., Godwin, I.D., and Huang, L.B. 2007a. Genotypic variation of iron partitioning in rice grain. J. Sci. Food Agric., 8:2049-2054.

Prom-u-Thai, C., Sanchai, C., Rerkasem, B., and Jamjod, S. 2007b. Effect of grain morphology on degree of milling and iron loss in rice. Cereal Chem., 84:384-388.

Rao, P.S., Bal, S., and Goswami, T.K. 2007. Modelling and optimisation of drying variables in thin layer drying of parboiled paddy. J. Food Engg, 78: 480-487.

Renjie, D., Zhanhui, L., Zhuqing, L., Shoji, K., and Wei, C. 2009. Effect of drying and tempering on rice fissuring analysed by integrating intra-kernel moisture distribution. J. Food Engg, 97: 161-167.

RKMP, Rice Knowledge Management Portal http://www.rkmp.co.in

Rohrer, C. A., and Siebenmorgen. T. J. 2004. Nutraceutical concentrations within the bran of various rice kernel thickness fractions. Bios. Engg, 88: 453-460.

Sajawan, K. S., Laplan, D.I., Mittra, B. N., and Pandey, H. K. 1990. Influence of the postharvest operations on the milling quality of rice. Intl. J. Trop. Agri., 8: 304-309.

Sarker, N. N., Kunze, O. R., and Strouboulis, T. 1996. Transient moisture gradients in rough rice mapped with finite element model and related to fissures after heated air drying. Transactions of the ASAE, 39: 625-631.

Schluterman, D. A., and Siebenmorgen, T. J. 2007. Relating rough rice moisture content reduction and tempering duration to head rice yield reduction. Transactions of the ASAE, 50:137-142.

Sharma, A. D., and Kunze, O.R. 1982. Postdrying fissure developments in rough rice. Transactions of the ASAE, 25:465-468, 474.

Sharma, G. P., Verma R. C., and Pathare, P. B. 2005. Thin-layer infrared radiation drying of onion slices. J. Food Engg, 67: 361-366.

Siebenmorgan, T. J., Yang, W., and Sun, Z. 2004. Glass transition temperature of rice kernels determined by dynamic mechanical thermal analysis. Transactions of ASAE, 47: 835-839.

Siebenmorgen, T. J., Matsler, A. L., and Earp, C. F. 2006. Milling characteristics of rice cultivars and hybrids. Cereal Chem., 83:169172.

Sila, B., 1999. Kinetics on colour changes in rice due to parboiling. J. Food Engg, 29: 99-106.

Silva, J.S., and Corrêa, P.C. 2000. Structure, composition and properties of the grains. Brazil: Maria Institute.

Singh, N., Kaur, Lovedeep, Navdeep, S. S., and Sekhon, K. S. 2005. Physicochemical, cooking and textural properties of milled rice from different Indian rice cultivars. Food Chem., 89:253-259.

Somchart, S., Adisak, N., Athikom, J., and Chaiyong, T. 2005. Parboiling brown rice using super-heated steam fluidization technique. J. Food Engg, 75: 423-432.

Soponronnarit, S., and Prachayawarakorn, S. 1994. Optimum strategy for fluidized bed paddy drying. Drying Technol., 12: 16671686.

Soponronnarit, S., Wetchakama, S., Swasdisevi, T., and Poomsa-ad, N. 1999. Managing moist paddy by drying, tempering and ambient air ventilation. Drying Technol., 17:335-344.

Steffe, J. F., 1979. Moisture diffusion and tempering in the drying of rough rice. Ph.D. Thesis, Department of Agricultural Engineering, University of California, Davis.

Steffe, J. F., and Singh, R. P. 1980. Theoretical and practical aspects of rough rice tempering. Transactions of the ASAE, 23: 775-782.

Stipe, D. R., Wratten, F. T., and Miller, M. F. 
1972. Effects of various methods of handling brown rice on milling and other quality parameters. Louisiana Agricultural Experiment Station Annual Program Rep., Rice Exp. Stn. 113.

Sun, H., and Siebenmorgen, T. J. 1993. Milling characteristics of various rough rice kernel thickness fractions. Cereal Chem., 70: 727733.

Sutherland, J. W., and Ghaly, T. F. 1992. Rapid fluid-bed drying of paddy rice in the humid tropics, In: Proceedings of the $13^{\text {th }}$ ASEAN Conference of Grain Post-harvest Technology, pp. 1-12. Brunei, Darussalam.

Takuma, G., Fumihiko, T., Daisuke, H., and Toshitaka. 2011. Incidence of open crack formation in short-grain polished rice during soaking in water at different temperatures. $J$. Food Engg, 103: 457-463.

Tanaka, F., Ide, Y., Kinjo, M., Genkawa, T., Hamanaka D., and Uchino, T. 2010. Development of thick layer re-wetting model for brown rice packaged with LDPE and PBT films. J. Food Engg, 101:223-227.

Thanit, S., Weera, S., Warunee, T., and Somchart, S. 2009. Effect of pre-steaming on production of partially-parboiled rice using hot-air fluidization technique. J. Food Engg, 96: 455-462.

Vasquez, V.R., Braganza, A., and Coronella, C.J. 2011. Molecular thermodynamics modeling of equilibrium moisture in foods. J. Food Engg, 103:103-114.

Wasserman, T., Ferrel, R. E., Houston, D. F., Breitwien, E., and Smith, G. S. 1964. Tempering western rice. Rice J., 67:16-17, 20-22.

Wathanyoo, R., Adisak, N., Warunee, T., and Somchart, S. 2004. Comparative study of fluidized bed paddy drying using hot air and superheated steam. J. Food Engg, 71: 28-36.

Yadav, B. K., and Jindal, V. K. 2001. Monitoring milling quality of rice by image analysis.
Comp Electro Agric., 33: 19-33.

Yadav, B. K., and Jindal, V. K. 2007. Changes in head rice yield and whiteness during milling of rough rice Oryza sativa L. J. Food Engg, 86: 113-121.

Yan, T.Y., Hong, J.H., and Chung, J.H. 2005. An improved method for production of white rice with embryo in a vertical mill. Bios. Engg, 92: 317-323.

Yang, W., Jia, C.C., Siebenmorgen, T. J., Howell, T.A., and Cnossen, A.G. 2002. Intra-kernel rice moisture responses to drying and tempering treatments by finite element simulation. Transactions of the ASAE, 45:1037-1044.

Yang, W., Siebenmorgen, T. J., Jia, C., Howell, T. A., Meullenet, J. F., and Cnossen, A. G. 2000. Rice kernel drying behaviour in a cross-flow dryer in relation to a glass transition state diagram. In: Proceedings of 2000 Rice Technical Working Group Conference, Biloxi, MS.

Yang, W., Siebenmorgen, T.J., Thielen, T.P.H., and Cnossen A.G. 2003. Effect of Glass Transition on Thermal Conductivity of Rough Rice. Bios. Engg, 84: 193-200.

Zhang, Q., and Litchfield, J. B. 1991. An optimization of intermittent corn drying in a laboratory scale thin layer. Drying Technol. 9: 383-395.

Zhang, W., Yang, W., and Sun, Z. 2005. Mechanical properties of sound and fissured rice kernels and their implications for rice breakage. J. Food Engg, 68: 65-72.

Zhu, K., Zou, J., Chu Z., and Li, X. 2002. Heat and mass transfer of seed drying in a two pass infrared radiation vibrated bed. Heat Transfer-Asian Research, 3:141-147.

Zoerb, G.C. 1958. Mechanical and rheological properties of grain. $\mathrm{PhD}$ Thesis, Michigan State University, East Lansing, MI.

\section{How to cite this article:}

Jagbir Rehal, Gagan Jyot Kaur and Singh, A.K. 2017. Influence of Milling Parameters on Head Rice Recovery: A Review. Int.J.Curr.Microbiol.App.Sci. 6(10): 1278-1295. doi: https://doi.org/10.20546/ijcmas.2017.610.152 